\title{
ARTICLE
}

Stem cell biology

\section{Danger-associated molecular pattern molecules take unexpectedly a central stage in NIrp3 inflammasome-caspase-1-mediated trafficking of hematopoietic stem/progenitor cells}

\author{
Arjun Thapa ${ }^{1} \cdot$ Mateusz Adamiak $\mathbb{D}^{2} \cdot$ Kamila Bujko $^{1} \cdot$ Janina Ratajczak $^{1} \cdot$ Ahmed K. Abdel-Latif $^{3} \cdot$ Magda Kucia $^{1,2} \cdot$ \\ Mariusz Z. Ratajczak (iD) ${ }^{1,2}$
}

Received: 21 November 2020 / Revised: 14 December 2020 / Accepted: 25 January 2021 / Published online: 23 February 2021

(c) The Author(s) 2021. This article is published with open access

\begin{abstract}
Like their homing after transplantation to bone marrow (BM), the mobilization of hematopoietic stem/progenitor cells (HSPCs) is still not fully understood, and several overlapping pathways are involved. Several years ago our group proposed that sterile inflammation in the BM microenvironment induced by pro-mobilizing agents is a driving force in this process. In favor of our proposal, both complement cascade (ComC)-deficient and Nlrp3 inflammasome-deficient mice are poor G-CSF and AMD3100 mobilizers. It is also known that the Nlrp3 inflammasome mediates its effects by activating caspase-1, which is responsible for proteolytic activation of interleukin-1 $\beta$ (IL-1 $\beta$ ) and interleukin-18 (IL-18) and their release from cells along with several danger-associated molecular pattern molecules (DAMPs). We observed in the past that IL-1 $\beta$ and IL-18 independently promote mobilization of HSPCs. In the current work we demonstrated that caspase-1-KO mice are poor mobilizers, and, to our surprise, administration of IL-1 $\beta$ or IL-18, as in the case of Nlrp3-KO animals, does not correct this defect. Moreover, neither Caspase-1-KO nor Nlrp3-KO mice properly activated the ComC to execute the mobilization process. Interestingly, mobilization in these animals and activation of the ComC were both restored after injection of the DAMP cocktail eATP + HGMB1+S100A9, the components of which are normally released from cells in an Nlrp3 inflammasome-caspase-1-dependent manner. In addition, we report that caspase-1-deficient HSPCs show a decrease in migration in response to BM homing factors and engraft more poorly after transplantation. These results for the first time identify caspase-1 as an orchestrator of HSPC trafficking.
\end{abstract}

\section{Introduction}

Research on enhancing egress of hematopoietic stem/progenitor cells (HSPCs) from bone marrow (BM) into

Supplementary information The online version contains supplementary material available at https://doi.org/10.1038/s41375021-01158-9.

Mariusz Z. Ratajczak

mzrata01@louisville.edu

1 Stem Cell Institute at James Graham Brown Cancer Center, University of Louisville, Louisville, KY, USA

2 Center for Preclinical Studies and Technology, Department of Regenerative Medicine at Medical University of Warsaw, Warsaw, Poland

3 Division of Cardiovascular Medicine, Gill Heart Institute, University of Kentucky, Lexington, KY, USA peripheral blood (PB) by administration of pro-mobilizing drugs seeks to optimize the regimens now available in the clinic to harvest enough cells for transplantation purposes. One has to take into consideration (i) that some patients mobilize poorly, (ii) the overall costs involved in this procedure, and (iii) HSPC donor convenience [1-3]. In our previous work we demonstrated that the distal part of the complement cascade (ComC) is important for optimal mobilization of HSPCs. Mice deficient in the fifth component of complement (C5) are poor mobilizers [4, 5], and weak activation of $\mathrm{C} 5$ correlates with poor mobilization in patients $[4,6]$. Based on these findings, we became interested in the role of other elements of innate immunity that are involved in this process.

Recently, we discovered that the Nlrp3 inflammasome, which is expressed in innate immunity cells and HSPCs, plays an important role in the egress of HSPCs from BM into PB. We reported that Nlrp3 inflammasome-deficient mice are poor mobilizers in response to standard drugs 
employed in the clinic, such as cytokine granulocyte colony-stimulating factor (G-CSF) and the CXCR4 receptor blocking agent and partial agonist [7-9]. The Nlrp3 inflammasome protein complex is located in the cytoplasm of innate immunity cells and, as we demonstrated recently, also in HSPCs in an inactive form. Upon activation, the complex becomes a functional protein aggregate composed of several Nlrp3 molecules (speck complexes) containing Nlrp3 proteins, ASC, and pro-caspase-1 [10-14]. In response to Nlrp3 activation, pro-caspase-1 becomes active caspase-1 and cleaves several proteins into their mature forms, thereby activating them inside cells. The important targets are pro-interleukin-1 $\beta$ (IL-1 $\beta$ ) and pro-interleukin-18 (IL-18), which after cleavage are released from cells as potent proinflammatory mediators [10-12, 14]. Activated caspase-1 also cleaves gasdermin-D protein [15], which is an effector protein for forming pores in cell membranes. Gasdermin-D pores are also important in the release from cells of several danger-associated molecular patterns (DAMPs), such as extracellular adenosine triphosphate (eATP), high mobility group box 1 (HMGB1) protein, and S100 calcium-binding protein A9 (S100A9) [16-21], which are directly or indirectly involved in activation of the ComC $[4,5,16,21]$.

It is known that, as an important mediator involved in innate immunity responses, the Nlrp3 inflammasome plays pleotropic roles in regulating the biology of cells. If properly activated, it promotes cell trafficking; however, if hyperactivated, it may perturb the cell's osmotic potential, leading to cell swelling and a lytic, highly inflammatory form of programmed cell death known as pyroptosis $[10,11,15,22,23]$. In our previous work we demonstrated that injection of the Nlrp3 inflammasome-activation mediators IL-1 $\beta$ or IL-18 into mice induces mobilization of functional HSPCs [7-9, 24]. Based on the fact that the Nlrp3 inflammasome activates caspase-1 to release these cytokines from cells, we became interested in whether caspase-1 deficiency would result in poor mobilization. Here we report that, indeed, mice that are caspase-1 deficient (caspase-1 KO) are poor mobilizers. To our surprise, however, as is the case for Nlrp3-KO mice, the poor mobilization status in caspase-1-KO mice is not reversed by administration of recombinant IL-1 $\beta$ or IL-18.

To address this unexpected observation, we focused on the role of the Nlrp3 inflammasome-caspase-1 axis in the release of DAMPs, which are activators of the ComC that are required for optimal mobilization of HSPCs. We found that poor mobilization status in caspase-1-KO and Nlrp3KO mice is restored to normal status after injection of DAMPs, which are correlated with enhanced activation of the ComC. Thus, our results further support important roles for innate immunity, BM sterile inflammation in response to pro-mobilizing agents, and the involvement of Nlrp3 inflammasome-released DAMPs, which activate the ComC to ensure optimal egress of HSPCs from BM into PB. Moreover, we also report that caspase-1-deficient HSPCs show a decrease in migration in response to BM homing factors and engraft more poorly after transplantation. Overall, for the first time our results identify caspase- 1 as an orchestrator of HSPC trafficking.

\section{Materials and methods}

\section{Animals}

Pathogen-free, 6-8-week-old female C57BL/6J wild-type (WT), B6.129S6-Nlrp3 $3^{\text {tm1Bhk} / J ~(N l r p 3-K O), ~ a n d ~ B 6 N .129 S 2-~}$ Casp1tm1Flv/J (Caspase-1-KO) mice were purchased from the Central Laboratory for Experimental Animals, Medical University of Warsaw or the Jackson Laboratory (Bar Harbor, ME, USA) at least 2 weeks before experiments. Animal studies were approved by the Animal Care and Use Committee of the Warsaw Medical University (Warsaw, Poland) and the Institutional Animal Care and Use Committee of the University of Louisville (Louisville, KY, USA).

\section{In vitro mobilization studies}

Mice were mobilized with G-CSF $(180 \mu \mathrm{g} / \mathrm{kg}$ per day; Amgen, Thousand Oaks, CA, USA) for 4 days by subcutaneous injection or AMD3100 (5 mg/kg; Sigma-Aldrich, St. Louis, MO, USA) for 1 day via intraperitoneal injection (IP). Depending on the experimental setup, mice were also injected once with IL-1 $\alpha$ or IL-33 (1 $\mu \mathrm{g}$ per mouse) or a mixture of IL- $1 \beta$ and IL-18 (0.5 $\mu$ g each per mouse; Sino Biological, Beijing) via IP. In some experiments, mice were injected with a mixture of interleukins IL-1 $\beta$ and IL-18 $(0.5 \mu \mathrm{g}$ each per mouse) and/or a DAMP molecule cocktail (ATP [3 mg/kg; Sigma-Aldrich, St. Louis, MO, USA] + HMGB1 [1.5 $\mu \mathrm{g}$; Sino Biological, Beijing] + S100A9 [2 $\mu \mathrm{g}$; Sino Biological, Beijing]) per mouse in the presence of AMD3100 or G-CSF. The DAMP cocktail was injected each day for 3 days for the G-CSF mobilization group and once for the AMD3100 mobilization group. In a separate experiment, mice were also injected with the caspase-1 inhibitor VX765 [25] (40 mg/kg; AdooQ Biosciences, Irvine, CA, USA) in the presence of AMD3100 or G-CSF by IP. VX765 was injected once every day for 6 days.

The mice receiving interleukin(s), VX765, or a cocktail of interleukins and DAMPs in the presence of G-CSF were bled from the retro-orbital plexus $(6 \mathrm{~h}$ after the last injection), and blood samples were drawn for plasma and hematology analysis. PB from these mice was obtained from the vena cava (with a 25 -gauge needle and 1-ml syringe containing $250 \mathrm{U}$ heparin). The blood samples from 
AMD3100-administered groups of animals were collected $1 \mathrm{~h}$ after injection(s). PB mononuclear cells (PBMNCs) were obtained by hypotonic lysis of red blood cells (RBCs) in BD Pharm Lyse buffer (BD Biosciences, San Jose, CA, USA) as described before $[4,7]$.

\section{Murine bone marrow-derived mononuclear cells (BMMNCs)}

Cells were obtained by flushing experimental mouse tibias and femurs. RBCs were lysed with BD Pharm Lyse buffer (BD Biosciences, San Jose, CA, USA), washed, and resuspended in appropriate media $[4,7]$.

\section{Evaluation of HSPC mobilization}

For evaluation of circulating colony-forming unit-granulocyte/macrophage (CFU-GM) and SKL cells, the following formulas were used: (number of white blood cells [WBCs] $\times$ number of CFU-GM colonies)/number of WBCs plated $=$ number of CFU-GM per $\mu \mathrm{l}$ of $\mathrm{PB}$; and (number of WBCs $\times$ number of SKL cells)/number of gated WBCs $=$ number of SKL cells per $\mu$ l of PB [4, 7].

\section{PB parameter counts}

To obtain WBC counts, $50 \mu \mathrm{l}$ of PB was taken from the retro-orbital plexus of mice into microvette EDTA-coated tubes (Sarstedt Inc., Newton, NC, USA) and run on a HemaVet 950FS hematology analyzer (Drew Scientific Inc., Oxford, CT, USA) within $2 \mathrm{~h}$ of collection [4, 7].

\section{Clonogenic CFU-GM and BFU-E assays}

PBMNCs were resuspended in methylcellulose base medium (R\&D Systems, Minneapolis, MN, USA). The medium for clonogenic CFU-GM assays was supplemented with 25 $\mathrm{ng} / \mathrm{ml}$ recombinant murine granulocyte/macrophage colonystimulating factor (mGM-CSF) and $10 \mathrm{ng} / \mathrm{ml}$ recombinant murine interleukin 3 (mIL-3). To perform burst-forming unit-erythroid (BFU-E) assays, BMMNC samples were suspended in methylcellulose supplemented with erythropoietin (5 U/ml) and IL-3 (10 ng/ml; PeproTech, Rocky Hill, NJ, USA). Cells were incubated for 7 days $\left(37^{\circ} \mathrm{C}\right.$, 95\% humidity, and $5 \% \mathrm{CO}_{2}$ ) for CFU-GM and 7 days for BFU-E assays. The CFU-GM and BFU-E colonies were scored using a simple inverted microscope (Olympus, Center Valley, PA, USA) [4, 7, 26].

\section{Flow cytometry analysis}

For the staining of $\mathrm{Lin}^{-} / \mathrm{Sca}-1^{+} / \mathrm{c}-\mathrm{Kit}^{+}$(SKL) cells, the following monoclonal antibodies were used: FITC-anti-CD117 (also known as c-Kit, clone 2B8; BioLegend, San Diego, CA, USA), PE-Cy5-anti-mouse Ly-6 A/E (also known as Sca-1, clone D7; eBioscience, San Diego, CA, USA), and anti-mouse lineage-marker antibodies, including antiCD45R (also known as B220, clone RA3-6B2), anti-Ter119 (clone TER-119), anti-CD11b (clone M1/70), anti-T cell receptor $\beta$ (clone H57-597), anti-Gr-1 (clone RB6-8C5), and anti-TCR $\gamma \delta$ (clone GL3) conjugated with PE (BD Biosciences, San Jose, CA, USA). Staining was performed in RPMI-1640 medium containing 2\% FBS. All monoclonal antibodies were added at saturating concentrations, and the cells were incubated for $30 \mathrm{~min}$ on ice, washed twice, and analyzed using an LSRII flow cytometer (BD Biosciences, San Jose, CA, USA) [4, 7, 26].

\section{Transwell migration assay}

RPMI-1640 medium containing 0.5\% BSA was used for migration-assay experiments. A $650-\mu \mathrm{l}$ volume of medium with or without stromal-derived factor 1 (SDF-1, $5 \mathrm{ng} / \mathrm{ml}$ ), sphingosine-1-phosphate (S1P, $0.1 \mu \mathrm{M})$, ATP $(10 \mu \mathrm{M})$, antimicrobial peptide cathelicidin bioactive fragment LL-37 $(2.5 \mu \mathrm{g} / \mathrm{ml})$, or a mixture of SDF-1 and LL-37 was added to the lower chamber of a Costar Transwell 24-well plate (Corning Inc., Corning, NY, USA). An aliquot $\left(1 \times 10^{6}\right.$ cells per $100 \mu \mathrm{l}$ ) of experimental mouse BMMNC suspension was loaded onto the upper chamber containing $5-\mu \mathrm{m}$ pore filters and then incubated for $3 \mathrm{~h}$ at $37^{\circ} \mathrm{C}$ in a $5 \% \mathrm{CO}_{2}$ incubator. Following incubation, an aliquot of cells from the lower chamber was harvested and resuspended in human methylcellulose base medium (R\&D Systems, Minneapolis, MN, USA) supplemented with murine GM-CSF $(25 \mathrm{ng} / \mathrm{ml})$ and IL-3 $(10 \mathrm{ng} / \mathrm{ml})$. Next, the cultures were incubated for 7 days at $37{ }^{\circ} \mathrm{C}$ in a $5 \% \mathrm{CO}_{2}$ incubator. The CFU-GM colonies were then counted under an inverted microscope [24, 26, 27].

\section{Short-term homing experiments}

WT mice were irradiated with a lethal dose of $\gamma$-irradiation (10 Gy). Twenty-four hours later, the animals were transplanted by injecting PKH67 green fluorescent dye (SigmaAldrich, St Louis, MO, USA)-labeled BMMNCs $\left(5 \times 10^{6} \%\right.$ $100 \mu \mathrm{l})$ from WT or Casp1-KO mice via tail vein injection. Twenty-four hours after transplantation, BMMNCs from the femurs were isolated by Ficoll-Paque density-gradient centrifugation. The cells were divided into two aliquots, one of which was analyzed by flow cytometer for PKH67positive cells, while the other was resuspended in human methylcellulose base medium supplemented with murine GM-CSF $(25 \mathrm{ng} / \mathrm{ml})$ and IL-3 $(10 \mathrm{ng} / \mathrm{ml})$. The cultures were incubated for 7 days at $37{ }^{\circ} \mathrm{C}$ in a $5 \% \mathrm{CO}_{2}$ incubator. The CFU-GM colonies were then counted using a simple inverted microscope $[24,26]$. 


\section{Evaluation of engraftment}

For engraftment experiments, WT mice were irradiated with a lethal dose of $\gamma$-irradiation (10 Gy). Twenty-four hours after irradiation, the animals were transplanted with $1.5 \times$ $10^{5} \mathrm{BM}$ cells from WT or Casp1-KO mice via tail vein injection. Twelve days after transplantation, the femora of transplanted mice were flushed with phosphate-buffered saline (PBS). BMMNCs were isolated by Ficoll-Paque density-gradient centrifugation. The cells were then plated in serum-free human methylcellulose base medium supplemented with mGM-CSF $(25 \mathrm{ng} / \mathrm{ml})$ and IL-3 $(10 \mathrm{ng} / \mathrm{ml})$. After 7 days of incubation $\left(37^{\circ} \mathrm{C}, 95 \%\right.$ humidity, and $5 \%$ $\mathrm{CO}_{2}$ ), the CFU-GM colonies were scored under an inverted microscope. Spleens from the transplanted mice were also removed and fixed in Telesyniczky's solution, and the CFU$\mathrm{S}$ colonies on the surface of the spleen were counted $[24,26]$.

\section{Recovery of leukocytes and platelets}

WT mice were irradiated with a lethal dose of $\gamma$-irradiation (10 Gy). Twenty-four hours later, the irradiated animals were transplanted with $7.5 \times 10^{5} \mathrm{BM}$ cells from WT or Casp1-KO mice via tail vein injection. At the time intervals indicated, the transplanted mice were bled from the retroorbital plexus to obtain WBC and platelet (PLT) counts, as described earlier [24, 26, 27]. Briefly, $50 \mu \mathrm{l}$ of PB was drawn into EDTA-coated Microvette tubes (Sarstedt Inc., Newton, NC, USA) and the samples run on a HemaVet 950FS hematology analyzer within $2 \mathrm{~h}$ of collection (Drew Scientific Inc., Oxford, CT, USA) [24, 26, 27].

\section{qRT-PCR analysis of NIrp3 inflammasome complex gene expression}

BMMNCs from WT or Casp1-KO experimental mice injected with PBS, AMD3100, or G-CSF were harvested, and the total RNA was isolated with the RNeasy Mini kit (Qiagen Inc., Germany), and the purified RNA was reverse transcribed with iScript reverse transcriptase (Biorad, Hercules, CA, USA). Quantitative evaluation of the target genes was then performed using SYBR Green PCR Master Mix reagents (Applied Biosystems, Carlsbad, CA, USA) and specific primers. The samples were run on an $\mathrm{ABI}$ Prism 7500 sequence detection system (Applied Biosystems, Carlsbad, CA, USA). The PCR cycling conditions were $95^{\circ} \mathrm{C}(15 \mathrm{~s}), 40$ cycles at $95^{\circ} \mathrm{C}(15 \mathrm{~s})$, and $60{ }^{\circ} \mathrm{C}$ (1 min). According to melting point analysis, only one PCR product was amplified under these conditions. The relative quantity of a target gene, normalized to the $\beta 2$-microglobulin gene as the endogenous control and relative to a calibrator, was expressed as $2^{-\Delta \Delta \mathrm{Ct}}$ (fold difference). The following primer pairs were used for analysis: $m I L-1 \beta$

forward primer: 5'-TCACAGCAGCACATCAACAA- $3^{\prime}$ reverse primer: $5^{\prime}$-TGTCCTCATCCTGGAAGGTC-3' $m I L-18$

forward primer: $5^{\prime}$-ACAACTTTGGCCGACTTCAC- $3^{\prime}$ reverse primer: $5^{\prime}$-GGGTTCACTGGCACTTTGAT- $3^{\prime}$ mAIM2

forward primer: 5'-AAAACTGCTCTGCTGCCTCT-3' reverse primer: $5^{\prime}$-GATGGCTTCCTGTTCTGCCA- $3^{\prime}$ $m N L R P 1$

forward primer: 5'-GCTGAATGACCTGGGTGATGG $\mathrm{T}-3^{\prime}$

reverse primer: 5'-CTTGGTCACTGAGAGATGCCT G-3'

$m N L R P 3$

forward primer: $5^{\prime}$-GCTGCTGAAGATGACGAGTG-3' reverse primer: $5^{\prime}$-TTTCTCGGGCGGGTAATCTT-3' $m A S C$

forward primer: $5^{\prime}$-GCCAGAACAGGCACTTTGTG-3' reverse primer: $5^{\prime}$-AGTCAGCACACTGCCATGC- $3^{\prime}$ $m H M G B 1$

forward primer: 5'-TAAAAAGCCCAGAGGCAAAA-3' reverse primer: $5^{\prime}$-GCSGCSATGGTCTTCCACCT- $3^{\prime}$ mS100A9

forward primer: 5'-TGGTGGAAGCACAGTTGG-3' reverse primer: 5'-CATCAGCATCATACACTCCTC AA- $3^{\prime}$

$m \beta 2 M$

forward primer: 5'-ATGCTATCCAGAAAACCCCTC AAAT-3

reverse primer: 5'-AACTGTGTTACGTAGCAGTTCA GTA-3 ${ }^{\prime}$

\section{Caspase-Glo $^{\circledR} 1$ inflammasome assay}

To measure caspase- 1 activity, the caspase-Glo ${ }^{\circledR} 1$ inflammasome assay kit (Promega, Madison, WI, USA) was used. Briefly, murine tibias and femurs from WT mice were flushed, and BMMNCs were obtained after lysis of the RBCs using $1 \times$ BD Pharm Lyse buffer (BD Pharmingen, San Jose, CA, USA). The cells were then suspended in RPMI medium containing $0.5 \%$ BSA $\left(0.2 \times 10^{6} / 50 \mu \mathrm{l}\right)$ and plated in a 96-well plate in the absence or presence of ATP (10 $\mu \mathrm{M})$, S1P $(0.1 \mu \mathrm{M})$, or SDF-1 $(100 \mathrm{ng} / \mathrm{ml})$. The plates were incubated at $37^{\circ} \mathrm{C}$ in $5 \% \mathrm{CO}_{2}$ for $3 \mathrm{~h}$. To measure caspase- 1 activity directly in cells, reconstituted Caspase-Glo ${ }^{\circledR}$ reagent, which contains a luminogenic caspase-1 substrate, Z-WEHD-aminoluciferin, was added to the samples. 
The samples were mixed gently and incubated at room temperature for $60 \mathrm{~min}$. The luminescence was measured using a plate-reading luminometer (Beckman Coulter TDX 8000, Brea, CA, USA) at 60, 90, and 120 min after adding the reagents.

\section{Enzyme-linked immunosorbent assay}

BMMNCs from WT or Casp1-KO or NLRP3 KO mice injected with the mixture of interleukins or interleukins and DAMPs in the presence or absence of AMD3100 or GCSF were isolated as described above. The residual RBCs were lysed using Lyse buffer (BD Biosciences, San Jose, CA, USA). Then, the samples were incubated in $0.5 \%$ BSA containing RPMI for $24 \mathrm{~h}$ at $37^{\circ} \mathrm{C}$ in a $5 \% \mathrm{CO} 2$ incubator. The culture supernatant was collected. A $100 \mu \mathrm{l}$ of the conditioned medium samples were used in this experiment $[24,28]$. The experiments were performed in triplicates using complement C5a mouse ELISA kit (Abcam, Cambridge, MA, USA) as described in manufacturer's protocol.

\section{Statistical analysis}

All results are presented as mean $\pm \mathrm{SD}$. Statistical analysis of the data was done using Student's $t$-test for unpaired samples, with $p \leq 0.05$ considered significant.

\section{Results}

\section{Effect of the IL-1 cytokine family on HSPC mobilization}

In our previous work we presented evidence that administration of IL-1 $\beta$ to normal WT mice induces effective mobilization of HSPCs [7-9]. We also demonstrated that a similar effect was obtained with another cytokine, IL-18, which, like IL-1 $\beta$, is released in a caspase-1-dependent manner in response to activated Nlrp3 inflammasomes [7-9]. Here we repeated mobilization experiments in WT animals and employed two other members of the IL-1 interleukin family, IL-1 $\alpha$ and IL-33 [29-31]. As shown in Fig. 1A, B, IL-1 $\alpha$, but not IL-33, promoted egress of HSPCs from BM into PB. This demonstrates that the promobilization effect is restricted to specific members of the IL-1 cytokine family, namely, IL- $1 \beta$ and IL- $1 \alpha$. In particular, IL-1 $\beta$ and IL-18 are products of activation of the Nlrp3 inflammasome, which we have demonstrated in the past as playing an important role in the trafficking of HSPCs [7-9, 24]. Therefore, we focused on the role of these cytokines, which are released in an Nlrp3 inflammasome-caspase-1-dependent manner.

\section{Caspase-1 KO mice are poor G-CSF and AMD3100 mobilizers}

Since both IL-1 $\beta$ and IL-18 are released from cells after cleavage of their pro-forms by caspase-1, in order to learn more about the role of caspase- 1 in the mobilization process, we mobilized WT mice with G-CSF and AMD3100 in the presence of the caspase- 1 inhibitor VX765 [25]. As expected, we found that these animals mobilized poorly (Supplementary Fig. 1). Next, to confirm this result we employed caspase-1-KO animals and mobilized them with G-CSF or AMD3100 (Fig. 1C, D). Again, the number of mobilized WBC, SKL cells, and clonogenic progenitors circulating in PB was reduced in caspase-1-KO animals compared with normal WT mouse controls.

We also evaluated the number of SKL cells and CFUGM and BFU-E clonogenic progenitors in the BM of caspase-1-KO mice under steady-state conditions and found that these animals have $\sim 10-12 \%$ higher numbers in BM (Supplementary Fig. 2). Since progenitor cells are released continuously from BM and circulate in $\mathrm{PB}$, this finding may indicate that, under steady-state conditions, egress of these cells from BM is also somewhat impaired. This question, however, requires further study.

\section{BMMNCs from caspase-1-KO mice show less-efficient migration in response to SDF-1, S1P, and eATP gradients and display worse homing and engraftment properties than cells from normal control animals}

Trafficking of HSPCs is regulated by selected chemotactic factors, such as SDF-1, S1P, and eATP [20, 24, 32-35]. Therefore, as a next step we evaluated the migratory responses of BMMNCs isolated from caspase-1-KO mice to these chemoattractants by employing the Transwell migration system. First, as shown in Fig. 2A, we confirmed that BMMNCs from WT mice respond to eATP, S1P, and SDF-1 stimulation by activation of caspase-1. Next, Fig. 2B shows impaired migration of caspase-1-KO CFU-GM clonogenic progenitors in response to these major HSPC chemoattractants. Caspase1-KO clonogenic progenitors also showed decreased chemotaxis in response to SDF-1 in the presence of cathelicidin (LL37), which sensitizes the chemotactic responsiveness of HSPCs, as we demonstrated in the past [4, 24, 26].

To better address this defective migration of caspase-1-KO HSPCs, we moved to an in vivo model in which we transplanted control WT mice with BMMNCs isolated from caspase-1-KO mice and compared homing and engraftment of these cells with transplantations performed with BMMNCs isolated from WT animals (Fig. 3). We found that the number of donor-derived, PKH67-labeled BMMNCs and the number of CFU-GM clonogenic progenitors (as enumerated $24 \mathrm{~h}$ after 

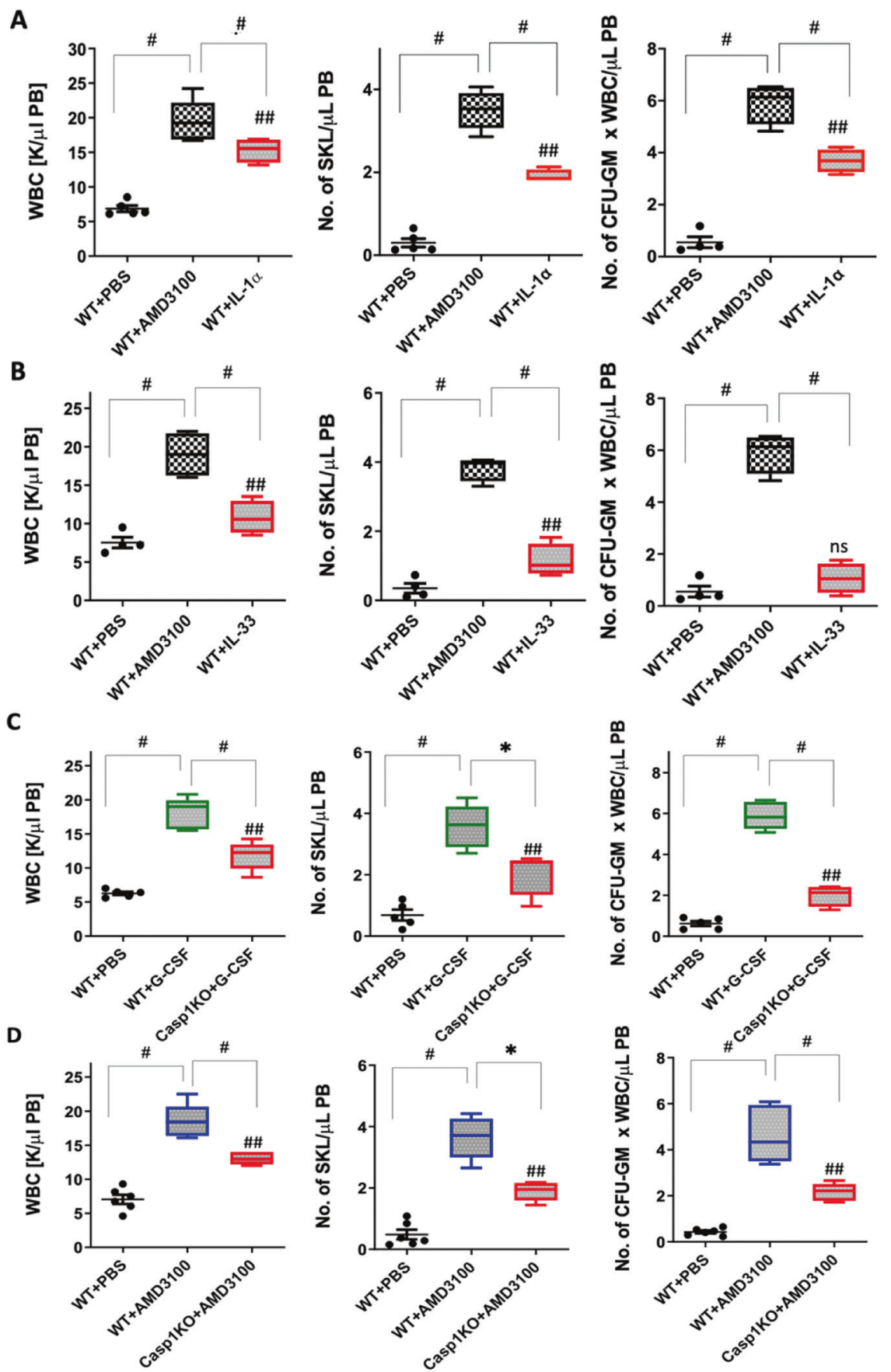

transplantation in $\mathrm{BM}$ from recipient mice, in a similar manner as day-12 colony-forming units in spleen [CFU-S] and day-12 CFU-GM clonogenic progenitors in BM) was reduced when BMMNCs from caspase-1-KO mice were transplanted. In parallel, we also observed a slowing in the recovery kinetics of leukocytes and blood platelets. This result indicates that HSPC expression of caspase-1 is involved not only in vitro but also in in vivo migration of HSPCs in response to $\mathrm{BM}$ chemotactic factors and affects their homing and engraftment in BM.
AMD3100- and G-CSF-induced expression of mRNAs for NIrp3 inflammasome components and crucial DAMPs is impaired in BMMNCs from caspase-1-KO animals

To address the observed differences at the molecular level, we evaluated changes in expression of mRNAs for Nlrp3 inflammasome components and selected DAMPs in BMMNCs in response to mobilization with AMD3100 and G-CSF (Fig. 4). We found that, in comparison with WT animals, caspase-1-KO mice have significantly reduced 
Fig. 1 G-CSF and AMD3100 mediated mobilization experiments in normal mice in response to $\mathrm{IL}-1 \alpha$ and $\mathrm{IL}-33$ and poor G-CSF and AMD3100 mobilization in caspase-1-KO animals. A WT mice were injected with PBS, AMD3100 ( $5 \mathrm{mg} / \mathrm{kg})$, or IL-1 $\alpha(1 \mu \mathrm{g} / \mathrm{mice})$, and peripheral blood (PB) parameters for WBCs (left), SKL cells (middle), and CFU-GM clonogenic progenitors (right) were analyzed. B WT mice were injected with PBS, AMD3100 (5 mg/kg), or IL-33 (1 $\mu \mathrm{g} /$ mice), and PB parameters for WBCs (left), SKL cells (middle), and CFU-GM clonogenic progenitors (right) were analyzed. AMD3100, IL- $1 \alpha$, and IL-33 were injected once. AMD3100-injected mice were sacrificed $1 \mathrm{~h}$ post injection, whereas the mice that had received IL- $1 \alpha$ or IL-33 were sacrificed $6 \mathrm{~h}$ post injection. To perform a CFU-GM colony assay, peripheral blood mononuclear cell (PBMNC) samples were cultured in human methylcellulose medium supplemented with growth factors. The PBMNCs were stained with appropriate antibodies, and the SKL cell population was analyzed using a flow cytometer. The number of SKL cells mobilized into PB was calculated using the formula: $\mathrm{WBCs} \times \mathrm{SKL}$ cells/gated $\mathrm{WBCs}=\mathrm{SKL}$ cells $/ \mu \mathrm{l}$. The number of $\mathrm{CFU}-\mathrm{GM} / \mu \mathrm{l}$ in $\mathrm{PB}$ was evaluated by the formula: [WBCs] $\times$ CFU-GM colonies/WBCs plated. The data are presented as means $\pm \mathrm{SE}$, and an unpaired Student's $t$-test was used for the determination of significance $\left({ }^{*} p \leq 0.05,{ }^{\#} p \leq 0.005\right.$, and ${ }^{\# \#} p \leq 0.005$ or ${ }^{\mathrm{ns}}$ no significant $\mathrm{WT}+\mathrm{PBS}$ vs WT+IL- $1 \alpha$ ). $\mathbf{C}$ Caspase-1-KO mice are poor G-CSF and AMD3100 mobilizers. WT mice were injected with PBS or G-CSF $(180 \mu \mathrm{g} / \mathrm{kg})$, while caspase-1-KO (Casp1-KO) mice were injected with G-CSF $(180 \mu \mathrm{g} / \mathrm{kg})$, and the PB parameter profiles for WBCs (left), SKL cells (middle), and CFU-GM clonogenic progenitors (right) were analyzed. PBMNC samples were cultured for CFUGM colonies, and stained PBMNCs were analyzed by flow cytometer for SKL cell analysis. D WT mice were injected with PBS or AMD3100 $(5 \mathrm{mg} / \mathrm{kg})$, while Casp1-KO mice were injected with AMD3100 (5 mg/kg), and the PB parameter profiles for WBCs (left), SKL cells (middle), and CFU-GM clonogenic progenitors (right) were analyzed. AMD3100 was injected once, whereas G-CSF was given on 4 consecutive days. AMD3100-injected mice were sacrificed $1 \mathrm{~h}$ post injection, whereas G-CSF-injected animals were sacrificed $6 \mathrm{~h}$ after the last injection. The numbers of SKL cells and CFU-GM progenitors mobilized into PB were calculated using the formula described in Materials and methods. The data are presented as means \pm SE, and an unpaired Student's $t$-test was used for the determination of significance $\left({ }^{*} p \leq 0.05,{ }^{\#} p \leq 0.005\right.$, and ${ }^{\# \#} p \leq 0.005 \mathrm{WT}+\mathrm{PBS}$ vs Casp1-KO+GCSF).

expression of mRNAs encoding Nlrp3, IL-1 $\beta$, IL-18, HMGB1, and S100A9 as well mRNAs for other inflammasomes, such as Aim2 and Nlrp1. This defective expression was particularly visible in BMMNCs from mice mobilized for 6 days with G-CSF.

\section{Neither IL-1 $\beta$ nor IL-18 mobilize HSPCs in caspase-1- KO or NIrp3-KO animals, but mobilization in these murine strains is enhanced after administration of a DAMP cocktail}

Next, to see whether co-administration of IL- $1 \beta$ and IL-18 would improve the poor mobilization status of caspase-1KO animals, we mobilized these mice with G-CSF or AMD3100, alone or in the presence of injected IL-1 $\beta+$ IL18 , and expected to see improvement in mobilization efficacy. To our surprise, however, we did not observe any positive effect on mobilization (Fig. 5A, B). Based on this result, we performed a similar experiment in Nlrp3-KO mice, and again we did not observe improvement in mobilization (Fig. 5C, D) in this poorly mobilizing murine strain, as reported in our previous work [7, 9].

We reported in the past that in vivo injection of a DAMP cocktail (eATP + HGMB1 + S100A9) enhances G-CSFinduced mobilization of HSPCs and activation of the ComC $[5,16,24,33]$. Since DAMPs are released from the cells in an Nlrp3 inflammasome-caspase-1-dependent manner, we employed this DAMP cocktail again to see whether we could enhance G-CSF- and AMD3100-induced mobilization in caspase-1-KO and Nlrp3 inflammasome-deficient, poorly mobilizing mice. We found that administration of this cocktail of DAMPs restored defective mobilization in caspase-1-KO animals (Fig. 5A, B), as in Nlrp3-KO mice (Fig. 5C, D).

DAMPs released into the extracellular space may activate the ComC, of which the distal part, involving the release of C5 cleavage fragments, is crucial for optimal egress of HSPCs from BM into PB [5, 16, 28, 36]. Figure 6 shows that the ComC is not efficiently mobilized in caspase-1-KO and Nlrp3-KO animals after administration of G-CSF or AMD3100, but its activation is significantly increased not by addition of IL- $1 \beta+\mathrm{IL}-18$ but in response to infused DAMPs. This is supported by performed Glow assay (Supplementary Fig. 3) to detect activated caspase-1 in Nlrp3-KO mice after administration of cocktail of DAMPs (eATP + HGMB1 + S100A9), and suggests involvement of other inflammasomes.

\section{Discussion}

The most important outcome of this work is the discovery that the pro-mobilizing effects of the Nlrp3 inflammasome-caspase-1 axis depend on the release of DAMPs from hematopoietic cells. This process is maintained, on the one hand, by an autocrine positive-feedback mechanism involving Nlrp3 inflammasome activation, and, on the other hand, by activators of the ComC that are required for optimal egress of HSPCs from BM into PB. As depicted in Fig. 7, this result also sheds new light on the role of IL-1 $\beta$ and IL-18 in the mobilization of HSPCs, in which they stimulate hematopoietic cells to release DAMPs to activate the ComC. Moreover, we demonstrated that caspase-1-deficient HSPCs show a decrease in migration in response to BM homing factors and engraft more poorly after transplantation. Overall, these results also, for the first time, identify caspase-1 as an important orchestrator of HSPC trafficking.

There are several overlapping pathways involved in the egress of HSPCs from their niches into the circulation 


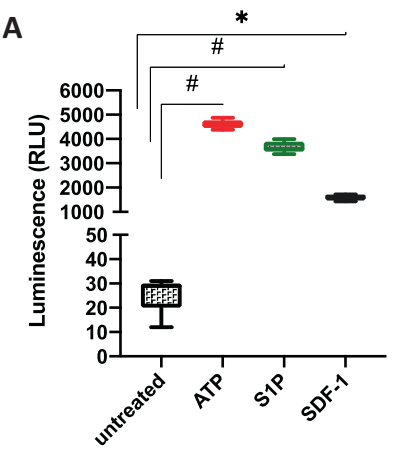

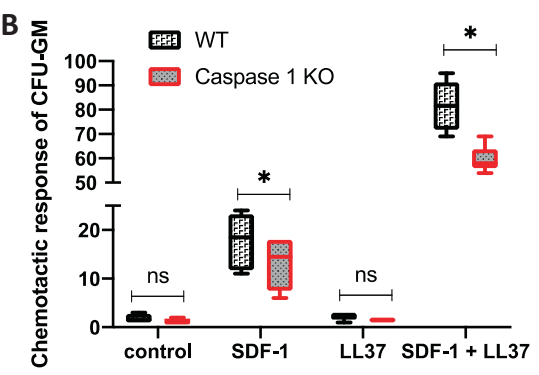

Fig. 2 Caspase-1 is activated in BMMNCs in response to $\mathrm{BM}$ chemoattractants, and caspase-1-KO BMMNCs show a decrease in chemotaxis. A luminescence measured in WT BMMNCs cultured in the absence or presence of ATP $(10 \mu \mathrm{M})$, S1P $(0.1 \mu \mathrm{M})$, or SDF $(100 \mathrm{ng} / \mathrm{ml})$ for $3 \mathrm{~h}$ at $37^{\circ} \mathrm{C}$ prior to adding Caspase- $1 \mathrm{Glo}^{\circledR} 1$ reagent. B The number of CFU-GM colonies formed from WT or Casp1-KO BMMNC samples recovered from the lower chamber of a 24-well

[37-44]. This process is initiated by pro-mobilizing cytokines (e.g., G-CSF and Gro- $\beta$ ), which are small molecular antagonists of receptors involved in the retention of HSPCs in BM niches (e.g., CXCXR4 and VLA-4), and by activation of signaling pathways involving mediators of purinergic signaling (eATP), adrenergic neurotransmitters, or bioactive phosphosphingolipids (S1P) [24, 26, 32-35, 45]. In parallel, evidence has accumulated that all of these factors that trigger the mobilization process induce a state of sterile inflammation in the BM microenvironment, which produces activation of the ComC $[4,5,28,46]$, release of proteolytic and lipolytic enzymes from cells [17, 40, 44, 47], and activation of the coagulation cascade $[4,46]$. In parallel, several proinflammatory mediators are also released that maintain this state, as are other mediators that control this process [16-19, 21, 48].

Our recent research proposes that central roles in maintaining sterile inflammation in BM are played by the innate immunity response and activation of the Nlrp3 inflammasome, which becomes activated both in innate immunity cells and, in parallel, in HSPCs, as we demonstrated [7-9, 24, 26]. This wide-ranging expression of Nlrp3 inflammasomes in cells involved in the immune response and in HSPCs should

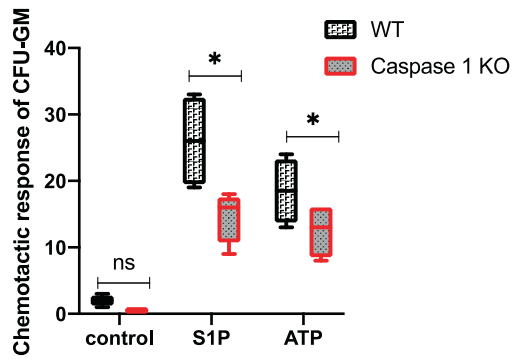

Costar Transwell plate into which four different sets of chemoattractants, including SDF-1 $(5 \mathrm{ng} / \mathrm{ml}), \mathrm{S} 1 \mathrm{P}(0.1 \mu \mathrm{M})$, ATP $(0.25 \mu \mathrm{g} / \mathrm{ml})$, LL-37 $(2.5 \mu \mathrm{g} / \mathrm{ml})$, or SDF-1 plus LL-37, were added to chemoattract the BMMNCs placed on the upper layer of the cell culture insert through a permeable membrane. The data are presented as means \pm SE. Unpaired Student's $t$-test was used for the determination of significance $\left(* p \leq 0.05\right.$ and $\left.{ }^{*} p \leq 0.005\right)$.

not be surprising, as all these cells have a common developmental precursor. Thus, we propose that all mediators that trigger the mobilization process merge at the Nlrp3 inflammasome and initiate activation of caspase- 1 and release of the proinflammatory cytokines IL-1 $\beta$ and IL-18 and several DAMPs from the cells.

Interestingly, IL-1 $\beta$ or IL-18 independently induce mobilization of HSPCs, as demonstrated in the past [7-9, 24], but they turned out to be ineffective in Nlrp3-KO and caspase-1$\mathrm{KO}$ mice, as we report here. This finding indicates that their role depends on the presence of a functional Nlrp3 inflammasome-caspase-1 axis in hematopoietic cells. Therefore, if injected in vivo, both cytokines activate Nlrp3 inflammasomes in BM cells, or, if secreted in a caspase-1-dependent manner from Nlrp3 inflammasome-expressing cells, promote and maintain a state of sterile inflammation in BM by employing autocrine/paracrine positive-feedback loops.

We report that the poorly mobilizing state in Nlrp3-KO and caspase-1-KO mice was reversed after injection of a cocktail of the most relevant DAMPs (eATP + HGMB1 + S100A9), which are secreted from cells in an Nlrp3 inflammasome-caspase-1-dependent manner. This result indicates that a crucial role of this axis in response to promobilizing cues is release of these mediators. We have 

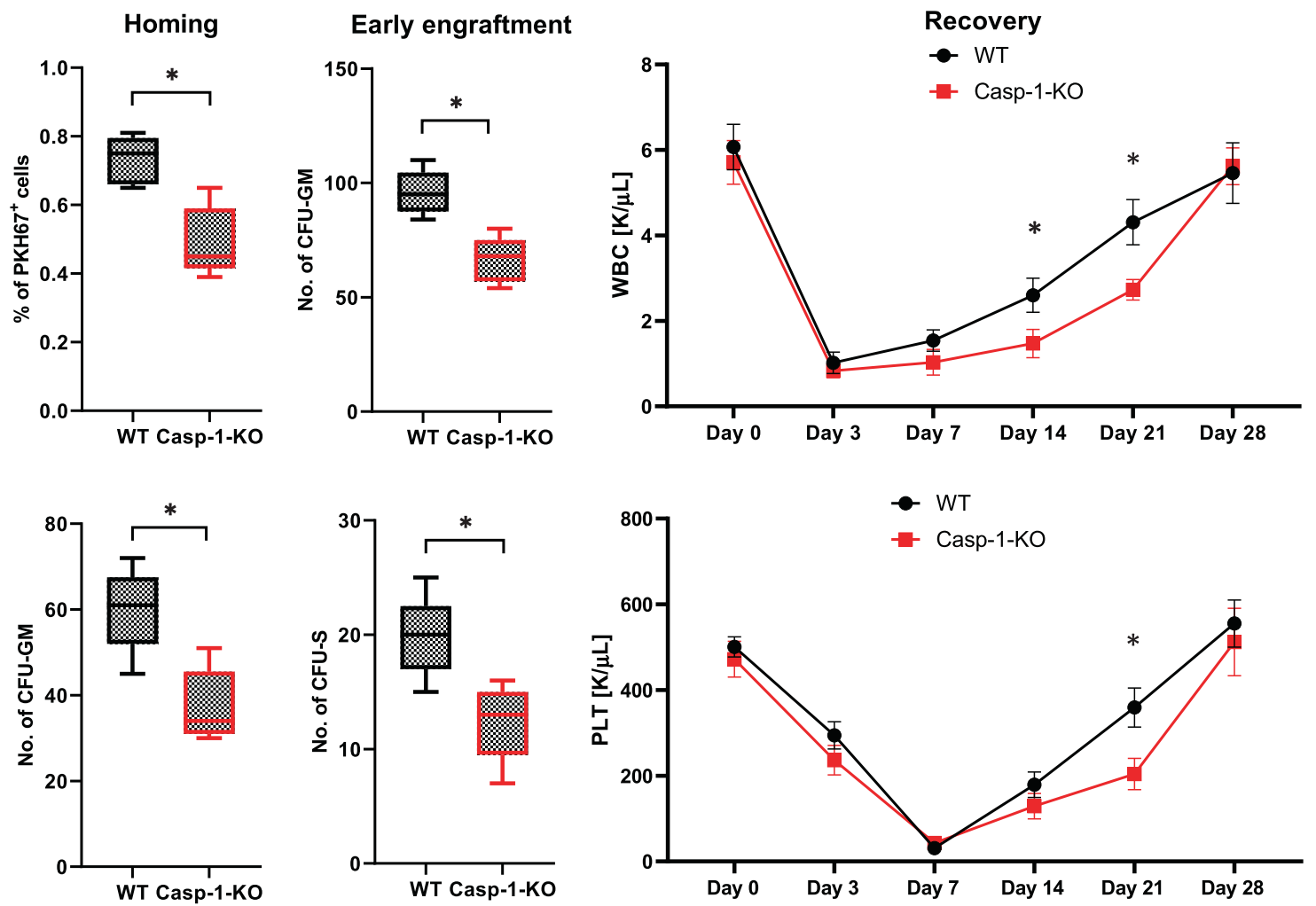

Fig. 3 Defective homing and engraftment of caspase-1-KO BMMNCs in control animals. Left panels (early homing experiments): FACS analysis of PKH67 green fluorescent-labeled BM cells harvested from lethally irradiated and transplanted WT mice. These mice were transplanted ( $24 \mathrm{~h}$ previously) with PKH67-labeled WT or Casp1-KO mouse BM cells (top, left panel), and CFU-GM clonogenic progenitors (bottom, left panel) formed from the BM samples were enumerated as described in Materials and methods. Middle panels (early engraftment experiments): 12 days after transplantation (WT or Casp1-KO BM cells)

into WT mice, BMMNCs or spleens from the transplanted mice were harvested and cultured for CFU-GM (top, middle panel) or CFU-S colonies (bottom, middle panel). No colonies were observed in lethally irradiated or normal control (untransplanted) mice. Right panels: lethally irradiated WT mice were transplanted with BMMNCs from WT or Casp1-KO mice, and peripheral blood samples were withdrawn for WBC (top, right panel) and platelet (PLT, bottom, right panel) analysis on days $0,3,7,14,21$, and 28 after transplantation. The data are presented as means $\pm \mathrm{SE}$, and an unpaired Student's $t$-test was used for determination of significance $\left({ }^{*} p \leq 0.05\right)$.

A

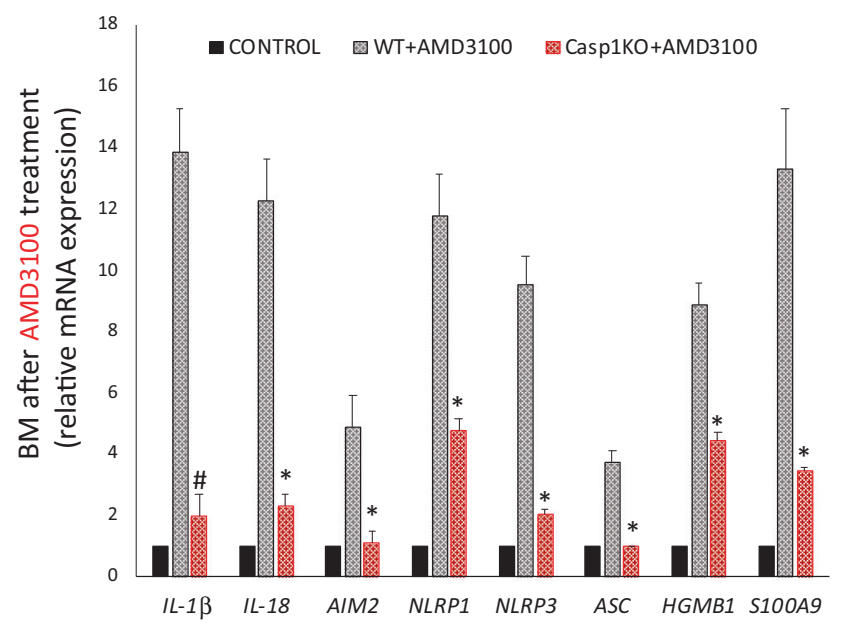

Fig. 4 Caspase-1-KO BMMNCs weakly upregulate mRNAs for inflammasome genes in response to G-CSF- and AMD3100induced mobilization. Left: normalized qRT-PCR expression analysis of IL-1 B, Il-18, Aim2, Nlrp1, Nlrp3, Asc (Pycard), Hmgb1, and S100A9 mRNAs from BMMNC samples obtained from WT or Casp1KO mice injected with PBS or AMD3100 (5 mg/kg). Right: relative
B

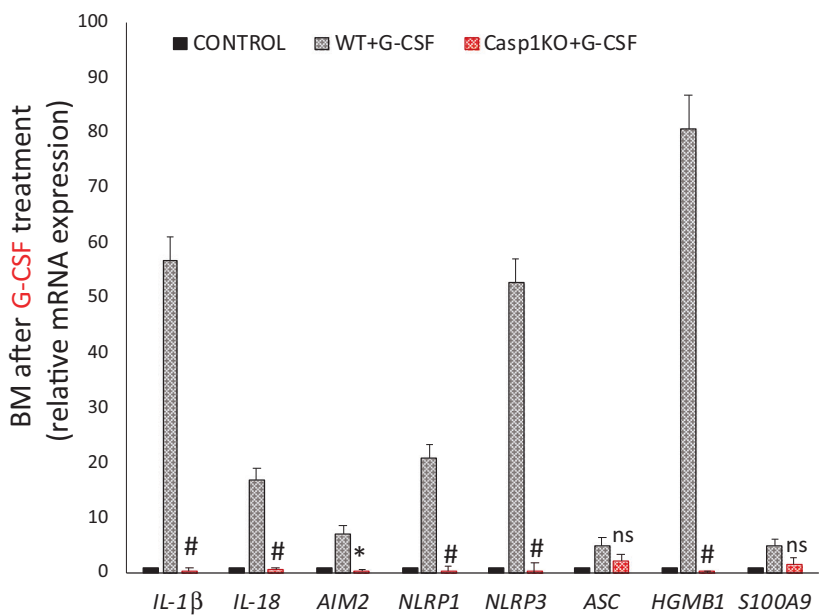

expression of IL-1 $\beta, I l-18$, Aim2, Nlrp1, Nlrp3, Asc (Pycard), Hmgb1, and S100A9 mRNAs in samples obtained from WT or Casp1-KO mice injected with PBS or G-CSF $(180 \mu \mathrm{g} / \mathrm{kg})$. The data represent the mean value \pm SEM for three independent experiments. Results of qRT-PCR were normalized to the $\beta 2$-microglobulin $(\beta 2 \mathrm{~m})$ expression levels. $* p \leq 0.05$ and ${ }^{*} p \leq 0.005$. 
A
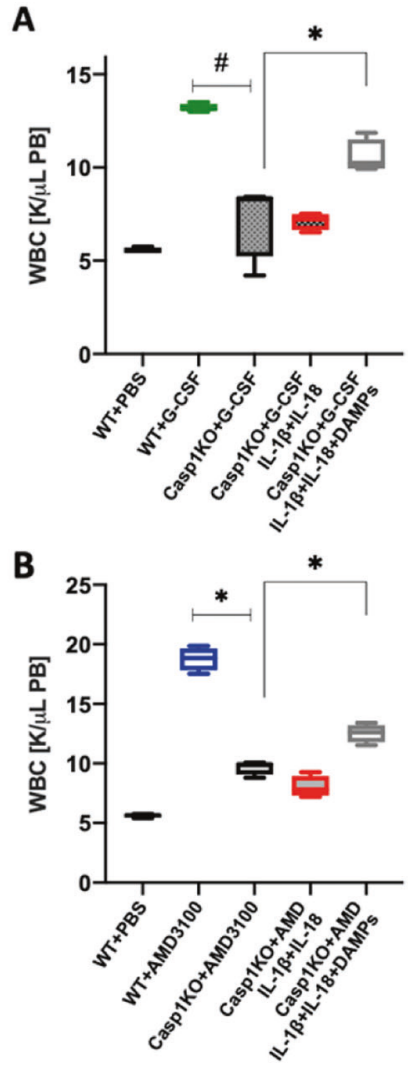

C

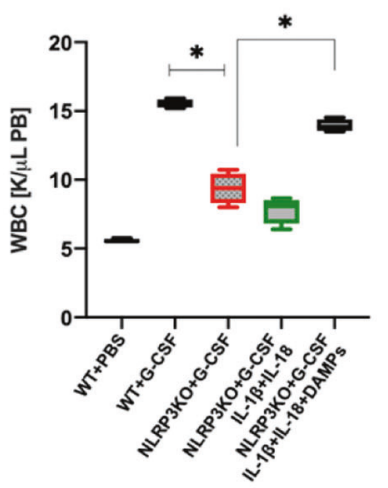

D

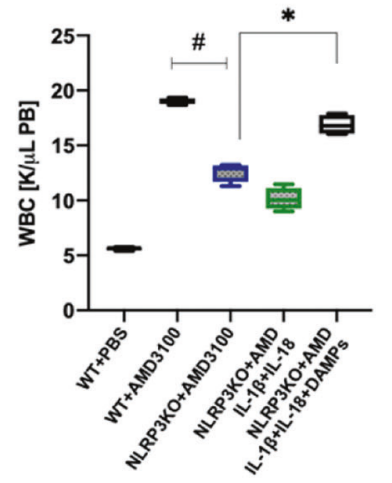

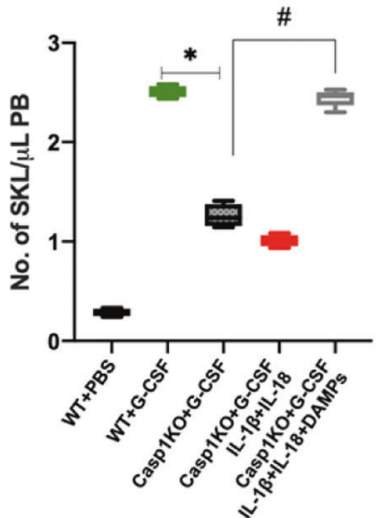
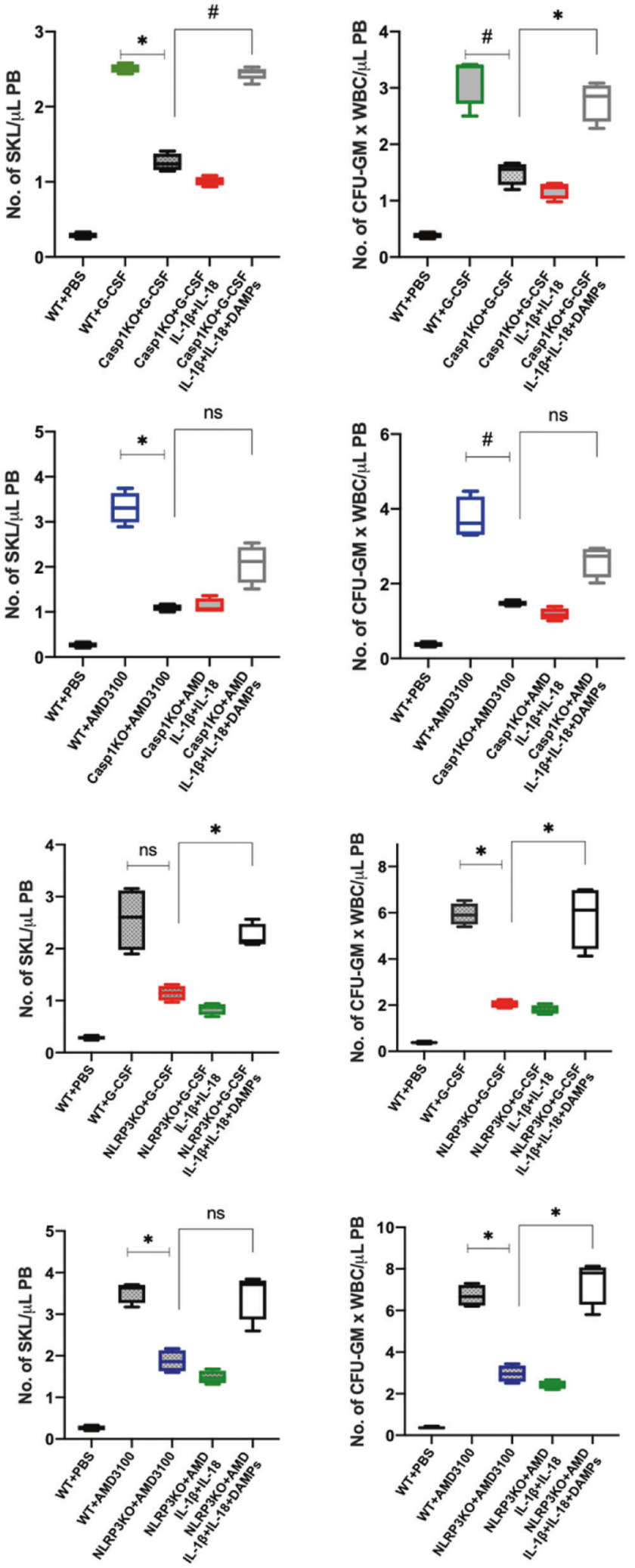

already reported that DAMPs injected into WT animals activate the ComC, as evidenced by detection of the C5a cleavage fragment in PB [5, 16, 24, 28]. This finding is supported by other published observations that DAMPs may activate the ComC in several experimental settings of inflammation or tissue damage [18, 19, 49, 50]. 
Fig. 5 G-CSF and AMD3100 mobilization in caspase-1-KO and Nlrp3-KO animals is not restored by supplementation with

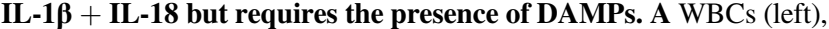
SKL cells (middle), and CFU-GM clonogenic progenitors (right) were obtained from WT mice injected with PBS or G-CSF $(180 \mu \mathrm{g} / \mathrm{kg})$ or Casp1-KO mice injected with G-CSF with or without a mixture of IL$1 \beta$ and IL-18 (0.5 $\mu$ g each per mouse) or a DAMP cocktail (ATP [3 mg/kg] + HMGB1 $[1.5 \mu \mathrm{g}]+$ S100A9 [2 $\mu \mathrm{g}]$ per mouse). B WBCs (left), SKL cells (middle), and CFU-GM clonogenic progenitors (right) were obtained from WT mice injected with PBS or AMD3100 $(5 \mathrm{mg} / \mathrm{kg})$ or Casp1-KO mice injected with AMD3100 with or without a mixture of IL-1 $\beta$ and IL-18 (0.5 $\mu$ g each per mouse) or a DAMP cocktail (ATP $[3 \mathrm{mg} / \mathrm{kg}]+$ HMGB1 $[1.5 \mu \mathrm{g}]+$ S100A9 $[2 \mu \mathrm{g}]$ per mouse). AMD3100 was injected once, whereas G-CSF was administered on 4 consecutive days. AMD3100-injected mice were sacrificed $1 \mathrm{~h}$ post injection, whereas G-CSF-treated animals were sacrificed $6 \mathrm{~h}$ after the last injection. The number of SKL cells and CFU-GM progenitors mobilized into PB was calculated using the formula described in Materials and Methods. The data are presented as means $\pm \mathrm{SE}$, and an unpaired Student's $t$-test was used for the determination of significance ( ${ }^{*} p \leq 0.05$ and $\left.{ }^{\#} p \leq 0.005\right)$. C WBCs (left), SKL cells (mid$\mathrm{dle}$ ), and CFU-GM clonogenic progenitors (right) were obtained from WT mice injected with PBS or G-CSF $(5 \mathrm{mg} / \mathrm{kg}$ ) or Nlrp3-KO mice injected with G-CSF with or without a mixture of IL-1 $\beta$ and IL-18 $(0.5 \mu \mathrm{g}$ each per mouse) or a DAMP cocktail (ATP $[3 \mathrm{mg} / \mathrm{kg}]+$ HMGB1 $[1.5 \mu \mathrm{g}]+$ S100A9 [2 $\mu \mathrm{g}]$ per mouse). D WBCs (left), SKL cells (middle), and CFU-GM clonogenic progenitors (right) obtained from WT mice injected with PBS or AMD3100 (5 mg/kg) or Nlrp3$\mathrm{KO}$ mice injected with AMD3100 $(5 \mathrm{mg} / \mathrm{kg})$ with or without a mixture of IL- $1 \beta$ and IL-18 ( $0.5 \mu \mathrm{g}$ each per mouse) or a DAMP cocktail (ATP $[3 \mathrm{mg} / \mathrm{kg}]+$ HMGB1 $[1.5 \mu \mathrm{g}]+$ S100A9 $[2 \mu \mathrm{g}]$ per mouse). AMD3100 was injected once, whereas G-CSF was administered on 4 consecutive days. AMD3100-injected mice were sacrificed $1 \mathrm{~h}$ post injection, whereas G-CSF-treated animals were sacrificed $6 \mathrm{~h}$ after the last injection. The numbers of SKL cells and CFU-GM progenitors mobilized into PB were calculated using the formula described in Materials and methods. The data are presented as means \pm SE, and an unpaired Student's $t$-test was used for the determination of significance $\left(* p \leq 0.05 ;{ }^{*} p \leq 0.005\right)$.

Thus, our results demonstrate for the first time the crucial role of the Nlrp3 inflammasome-caspase-1 axis in the release of DAMPs, which activate the ComC to execute the mobilization process. At the molecular level we report that caspase-1-KO BMMNCs exposed to G-CSF and AMD3100 show reduced levels of mRNAs encoding protein components of the Nlrp3 inflammasome. These cells also have reduced levels of mRNAs for other inflammasomes, including mRNAs for Nlrp1 and Aim1. Thus, future research should focus on the potential involvement of other members of the inflammasome family in regulating the trafficking of HSPCs. For example, it has been proposed that Aim1 inflammasomes are also activated by DAMPs [36, 51]. More importantly, the poor mobilization status of caspase-1-KO and Nlrp3-KO mice is correlated with defective activation of the ComC, and mobilization ability is restored after injection of DAMPs.

Moreover, we observed in the current work that caspase-1 promotes migration of HSPCs in response to BM-expressed
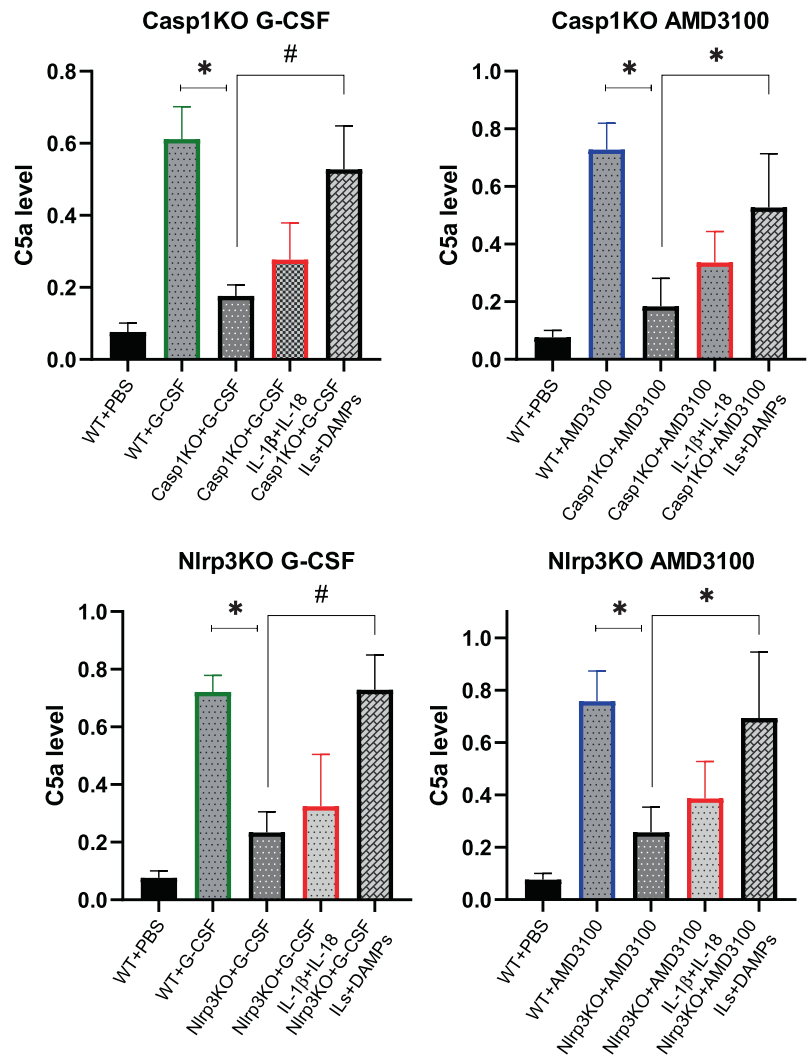

Fig. 6 DAMPs activate the ComC in BMMNCs. The levels of C5a protein in conditioned media harvested from BMMNC from WT or Casp1-KO (upper panel) mobilized by G-CSF or AMD3100 and from WT or Nlrp3-KO BMMNCs (lower panel), in the presence or absence of IL- $1 \beta+$ IL- 18 and in the presence of IL- $1 \beta+$ IL- $18+$ DAMPs (eATP, HMGB1, S1009A) were measured by ELISA. The data represent the mean value for two independent experiments $(* p \leq 0.05$ and $\left.{ }^{\#} p \leq 0.005\right)$.

chemoattractants, such as the major chemoattractant SDF-1 [24, 26, 34], as well as other supportive homing factors, such as S1P and eATP [20, 24, 26, 32, 45]. By employing functional immunofluorescence-based enzymatic assays, we demonstrated activation of caspase-1 in BMMNCs in response to $\mathrm{BM}$ homing factors. The requirement for caspase-1 in the normal migration of HSPCs has been shown in Transwell migration assays and was finally verified in vivo by demonstrating that BMMNCs from caspase-1-KO mice have defective homing and engraftment in WT animals. These results are similar to those reported in Nlrp3-KO animals [7, 8]. To explain this outcome at the molecular level, Nlrp3 inflammasome activation plays an important role in promoting membrane lipid raft formation, which assembles the cell-surfaceexpressed CXCR4 homing receptor for SDF-1 with downstream signaling proteins and thus optimizes the chemotactic homing response [24, 26, 32, 34, 45]. An important enhancer of membrane lipid raft formation is eATP, which is one of the major DAMPs [20, 24, 26] in addition to some of the cleavage fragments of the activated ComC, such as the anaphylatoxin 


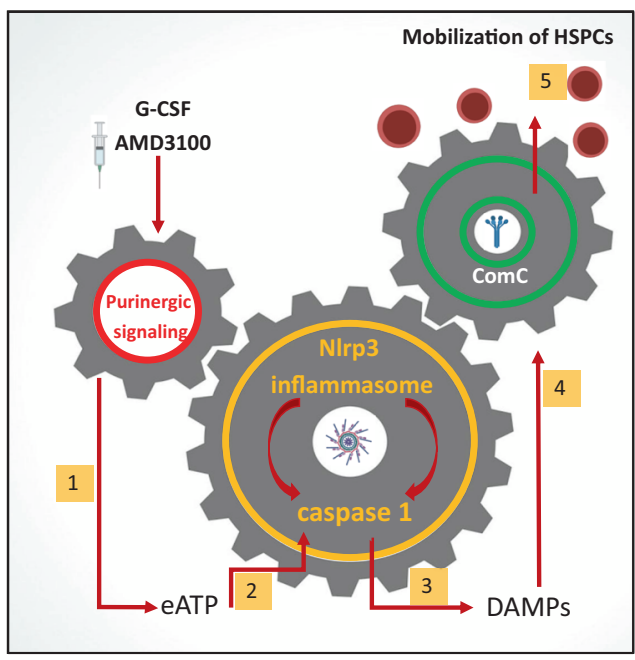

Fig. 7 Nlrp3 inflammasome-caspase-1-mediated release of DAMPs as a gear mechanism that couples purinergic signaling with the complement cascade (ComC) during HSPC mobilization. Promobilizing stimuli (e.g., G-CSF or AMD3100) (1) release ATP from activated innate immunity cells and HSPCs (2), which as extracellular ATP (eATP) activates intracellular inflammasomes via P2X4 and $\mathrm{P} 2 \mathrm{X} 7$ purinergic receptors (3). As a result of Nlrp3 inflammasome and caspase-1 activation, several DAMPs are released, including HMGB1 and S100a9 (4), that activate the ComC. Activation of the ComC leads to the release of $\mathrm{C} 5$ cleavage fragments that are crucial as demonstrated in the past (refs 4, 28, and 46) for optimal release of HSPCs from BM into PB (5).

C3a [52]. Lipid raft formation is also stimulated by certain other mediators of innate immunity, such as cathelicidin (LL37) $[24,26]$. Therefore, release of DAMPs, including eATP, activation of the ComC, and involvement of other mediators of activated innate immunity (e.g., LL-37) play important roles in this phenomenon and are defective in mice that lack a functional Nlrp3 inflammasome-caspase-1 axis.

It is important to mention that our past and recent results indicate the presence of an intrinsic auto-navigation mechanism in HSPCs that regulates their egress from BM as well as migration after transplantation to $\mathrm{BM}$ niches, which is modulated, positively or negatively, by external cues. Our current results support a central role for the Nlrp3 inflammasome-caspase-1 axis. This auto-navigation mechanism is activated in cells in response to HSPC chemoattractants and negatively regulated by heme oxygenase 1 [53], inducible nitric oxide synthetase [27], and endogenous adenosine [26,54], which are known negative regulators of Nlrp3 inflammasome activation. As would promoting activation of the Nlrp3-caspase-1 axis, inhibition of these negative regulators of stem cell trafficking would improve the efficacy of this process.

In conclusion, we have provided further evidence that the Nlrp3 inflammasome-caspase-1 axis promotes pharmacological mobilization, migration, and homing of HSPCs by (i) release of DAMPs that activate the intrinsic navigation mechanism in response to major BM chemoattractants in HSPCs, and (ii) promoting and maintaining a state of sterile inflammation in the BM microenvironment and activation of the ComC. Thus, these results support important roles for innate immunity, BM sterile inflammation in response to pro-mobilizing agents, and involvement of the Nlrp3 inflammasome and ComC in the trafficking of HSPCs and shed more light on the DAMPs that modulate $[4,5,21,26,39]$ these processes.

Acknowledgements This work was supported by NIH grants 2R01 DK074720, Stella and Henry Hoenig Endowment, and the Polish National Center OPUS grants UMO-2018/29/B/NZ4/01470 to MZR. AT was supported by NIH T32 HL134644 Training Grant to MZR.

\section{Compliance with ethical standards}

Conflict of interest The authors declare no competing interests.

Publisher's note Springer Nature remains neutral with regard to jurisdictional claims in published maps and institutional affiliations.

Open Access This article is licensed under a Creative Commons Attribution 4.0 International License, which permits use, sharing, adaptation, distribution and reproduction in any medium or format, as long as you give appropriate credit to the original author(s) and the source, provide a link to the Creative Commons license, and indicate if changes were made. The images or other third party material in this article are included in the article's Creative Commons license, unless indicated otherwise in a credit line to the material. If material is not included in the article's Creative Commons license and your intended use is not permitted by statutory regulation or exceeds the permitted use, you will need to obtain permission directly from the copyright holder. To view a copy of this license, visit http://creativecommons. org/licenses/by/4.0/.

\section{References}

1. Chabannon C, Le Corroller AG, Viret F, Eillen C, Faucher C, Moatti JP, et al. Cost-effectiveness of repeated aphereses in poor mobilizers undergoing high-dose chemotherapy and autologous hematopoietic cell transplantation. Leukemia. 2003;17:811-3.

2. Karpova D, Rettig MP, DiPersio JF. Mobilized peripheral blood: an updated perspective. F1000Res. 2019;8:1-14.

3. Pelus LM, Broxmeyer HE. Peripheral blood stem cell mobilization; a look ahead. Curr Stem Cell Rep. 2018;4:273-81.

4. Adamiak M, Abdelbaset-Ismail A, Suszynska M, Abdel-Latif A, Ratajczak J, Ratajczak MZ. Novel evidence that the mannanbinding lectin pathway of complement activation plays a pivotal role in triggering mobilization of hematopoietic stem/progenitor cells by activation of both the complement and coagulation cascades. Leukemia. 2017;31:262-5.

5. Borkowska S, Suszynska M, Ratajczak J, Ratajczak MZ. Evidence of a pivotal role for the distal part of the complement cascade in the diurnal release of hematopoietic stem cells into peripheral blood. Cell Transpl. 2016;25:275-82.

6. Reginia A, Kucharska-Mazur J, Jabłoński M, Budkowska M, Dołęgowska B, Sagan L, et al. Assessment of complement cascade components in patients with bipolar disorder. Front Psychiatry. 2018;9:614-614. 
7. Lenkiewicz AM, Adamiak M, Thapa A, Bujko K, Pedziwiatr D, Abdel-Latif AK, et al. The Nlrp3 inflammasome orchestrates mobilization of bone marrow-residing stem cells into peripheral blood. Stem Cell Rev Rep. 2019;15:391-403.

8. Ratajczak MZ, Adamiak M, Thapa A, Bujko K, BrzezniakiewiczJanus K, Lenkiewicz AM. NLRP3 inflammasome couples purinergic signaling with activation of the complement cascade for the optimal release of cells from bone marrow. Leukemia. 2019;33:815-25.

9. Ratajczak MZ, Bujko K, Cymer M, Thapa A, Adamiak M, Ratajczak J, et al. The Nlrp3 inflammasome as a "rising star" in studies of normal and malignant hematopoiesis. Leukemia. 2020;34:1512-23.

10. Groslambert M, Py BF. Spotlight on the NLRP3 inflammasome pathway. J Inflamm Res. 2018;11:359-74.

11. He Y, Hara H, Núñez G. Mechanism and regulation of NLRP3 inflammasome activation. Trends Biochem Sci. 2016;41:1012-21.

12. Malik A, Kanneganti TD. Function and regulation of IL- $1 \alpha$ in inflammatory diseases and cancer. Immunol Rev. 2018;281:124-37.

13. Gurung P, Malireddi RKS, Anand PK, Demon D, Vande Walle L, Liu Z, et al. Toll or interleukin-1 receptor (TIR) domaincontaining adaptor inducing interferon- $\beta$ (TRIF)-mediated caspase-11 protease production integrates Toll-like receptor 4 (TLR4) protein- and Nlrp3 inflammasome-mediated host defense against enteropathogens. J Biol Chem. 2012;287:34474-83.

14. Di A, Xiong S, Ye Z, Malireddi RKS, Kometani S, Zhong M, et al. The TWIK2 potassium efflux channel in macrophages mediates NLRP3 inflammasome-induced inflammation. Immunity. 2018;49:56-65.e54.

15. Shi J, Zhao Y, Wang K, Shi X, Wang Y, Huang H, et al. Cleavage of GSDMD by inflammatory caspases determines pyroptotic cell death. Nature. 2015;526:660-5.

16. Adamiak M, Abdel-Latif A, Ratajczak MZ. Purinergic signaling regulates mobilization of hematopoietic stem cells. Oncotarget. 2018;9:36052-4.

17. Chen GY, Nuñez G. Sterile inflammation: sensing and reacting to damage. Nat Rev Immunol. 2010;10:826-37.

18. Feldman N, Rotter-Maskowitz A, Okun E. DAMPs as mediators of sterile inflammation in aging-related pathologies. Ageing Res Rev. 2015;24:29-39.

19. Kang JW, Kim SJ, Cho HI, Lee SM. DAMPs activating innate immune responses in sepsis. Ageing Res Rev. 2015;24:54-65.

20. Lemoli RM, Ferrari D, Fogli M, Rossi L, Pizzirani C, Forchap S, et al. Extracellular nucleotides are potent stimulators of human hematopoietic stem cells in vitro and in vivo. Blood. 2004;104:1662-70

21. Kim SY, Son M, Lee SE, Park IH, Kwak MS, Han M, et al. Highmobility group box 1-induced complement activation causes sterile inflammation. Front Immunol. 2018;9:705.

22. Liu D, Zeng X, Li X, Cui C, Hou R, Guo Z, et al. Advances in the molecular mechanisms of NLRP3 inflammasome activators and inactivators. Biochem Pharm. 2020;175:113863.

23. Lu A, Li H, Niu J, Wu S, Xue G, Yao X, et al. Hyperactivation of the NLRP3 inflammasome in myeloid cells leads to severe organ damage in experimental lupus. J Immunol. 2017;198: 1119-29.

24. Cymer M, Brzezniakiewicz-Janus K, Bujko K, Thapa A, Ratajczak J, Anusz K, et al. Pannexin-1 channel "fuels" by releasing ATP from bone marrow cells a state of sterile inflammation required for optimal mobilization and homing of hematopoietic stem cells. Purinergic Signal. 2020;16:313-25.

25. Yu J, Nagasu H, Murakami T, Hoang H, Broderick L, Hoffman $\mathrm{HM}$, et al. Inflammasome activation leads to Caspase-1-dependent mitochondrial damage and block of mitophagy. Proc Natl Acad Sci USA. 2014;111:15514-9.
26. Adamiak M, Abdel-Latif A, Bujko K, Thapa A, Anusz K, Tracz $\mathrm{M}$, et al. Nlrp3 inflammasome signaling regulates the homing and engraftment of hematopoietic stem cells (HSPCs) by enhancing incorporation of CXCR4 receptor into membrane lipid rafts. Stem Cell Rev Rep. 2020;16:954-67.

27. Adamiak M, Abdelbaset-Ismail A, Moore JBT, Zhao J, AbdelLatif A, Wysoczynski M, et al. Inducible nitric oxide synthase (iNOS) is a novel negative regulator of hematopoietic stem/progenitor cell trafficking. Stem Cell Rev Rep. 2017;13:92-103.

28. Lee HM, Wu W, Wysoczynski M, Liu R, Zuba-Surma EK, Kucia $\mathrm{M}$, et al. Impaired mobilization of hematopoietic stem/progenitor cells in C5-deficient mice supports the pivotal involvement of innate immunity in this process and reveals novel promobilization effects of granulocytes. Leukemia. 2009;23:2052-62.

29. Alt C, Yuan S, Wu F, Stankovich B, Calaoagan J, Schopies S, et al. Long-acting IL-33 mobilizes high-quality hematopoietic stem and progenitor cells more efficiently than granulocyte colony-stimulating factor or AMD3100. Biol Blood Marrow Transpl. 2019;25:1475-85.

30. Dinarello CA. Immunological and inflammatory functions of the interleukin-1 family. Annu Rev Immunol. 2009;27:519-50.

31. Fibbe WE, Hamilton MS, Laterveer LL, Kibbelaar RE, Falkenburg JH, Visser JW, et al. Sustained engraftment of mice transplanted with IL-1-primed blood-derived stem cells. J Immunol. 1992;148:417.

32. Adamiak M, Borkowska S, Wysoczynski M, Suszynska M, Kucia M, Rokosh G, et al. Evidence for the involvement of sphingosine1-phosphate in the homing and engraftment of hematopoietic stem cells to bone marrow. Oncotarget. 2015;6:18819-28.

33. Adamiak M, Bujko K, Cymer M, Plonka M, Glaser T, Kucia M, et al. Novel evidence that extracellular nucleotides and purinergic signaling induce innate immunity-mediated mobilization of hematopoietic stem/progenitor cells. Leukemia. 2018;32:1920-31.

34. Lapidot T, Kollet O. The essential roles of the chemokine SDF-1 and its receptor CXCR4 in human stem cell homing and repopulation of transplanted immune-deficient NOD/SCID and NOD/ SCID/B2m(null) mice. Leukemia. 2002;16:1992-2003.

35. Juarez JG, Harun N, Thien M, Welschinger R, Baraz R, Pena AD, et al. Sphingosine-1-phosphate facilitates trafficking of hematopoietic stem cells and their mobilization by CXCR4 antagonists in mice. Blood. 2012;119:707-16.

36. Denes A, Coutts G, Lénárt N, Cruickshank SM, Pelegrin $P$, Skinner J, et al. AIM2 and NLRC4 inflammasomes contribute with ASC to acute brain injury independently of NLRP3. Proc Natl Acad Sci USA. 2015;112:4050-5.

37. Hoggatt J, Pelus LM. Many mechanisms mediating mobilization: an alliterative review. Curr Opin Hematol. 2011;18:231-8.

38. Kim J, Kim NK, Park SR, Choi BH. GM-CSF enhances mobilization of bone marrow mesenchymal stem cells via a CXCR4medicated mechanism. Tissue Eng Regen Med. 2019;16:59-68.

39. Nguyen TS, Lapidot T, Ruf W. Extravascular coagulation in hematopoietic stem and progenitor cell regulation. Blood. 2018;132:123-31.

40. Schuettpelz LG, Link DC. Regulation of hematopoietic stem cell activity by inflammation. Front Immunol. 2013;4:204.

41. Tay J, Levesque JP, Winkler IG. Cellular players of hematopoietic stem cell mobilization in the bone marrow niche. Int J Hematol. 2017;105:129-40.

42. Lévesque JP, Helwani FM, Winkler IG. The endosteal 'osteoblastic' niche and its role in hematopoietic stem cell homing and mobilization. Leukemia. 2010;24:1979-92.

43. Lapidot T, Kollet $\mathrm{O}$. The brain-bone-blood triad: traffic lights for stem-cell homing and mobilization. Hematol Am Soc Hematol Educ Program. 2010;2010:1-6.

44. Winkler IG, Pettit AR, Raggatt LJ, Jacobsen RN, Forristal CE, Barbier V, et al. Hematopoietic stem cell mobilizing agents G- 
CSF, cyclophosphamide or AMD3100 have distinct mechanisms of action on bone marrow HSC niches and bone formation. Leukemia. 2012;26:1594-601.

45. Seitz G, Boehmler AM, Kanz L, Möhle R. The role of sphingosine 1-phosphate receptors in the trafficking of hematopoietic progenitor cells. Ann NY Acad Sci. 2005;1044:84-89.

46. Adamiak M, Lenkiewicz AM, Cymer M, Kucia M, Ratajczak J, Ratajczak MZ. Novel evidence that an alternative complement cascade pathway is involved in optimal mobilization of hematopoietic stem/progenitor cells in Nlrp3 inflammasome-dependent manner. Leukemia. 2019;33:2967-70.

47. Golan K, Vagima Y, Ludin A, Itkin T, Cohen-Gur S, Kalinkovich A, et al. S1P promotes murine progenitor cell egress and mobilization via S1P1-mediated ROS signaling and SDF-1 release. Blood. 2012;119:2478-88.

48. Cruz CM, Rinna A, Forman HJ, Ventura AL, Persechini PM, Ojcius DM. ATP activates a reactive oxygen species-dependent oxidative stress response and secretion of proinflammatory cytokines in macrophages. J Biol Chem. 2007;282:2871-9.

49. Roh JS, Sohn DH. Damage-associated molecular patterns in inflammatory diseases. Immune Netw. 2018;18:e27-e27.
50. Weber B, Lackner I, Baur M, Gebhard F, Relja B, Marzi I, et al. DAMP-mediated cardiac dysfunction: cardiomyocytes as actors and target of innate immune response. J Immunol. 2020;204(1 Supplement): 144.118.

51. Hu B, Jin C, Li HB, Tong J, Ouyang X, Cetinbas NM, et al. The DNA-sensing AIM2 inflammasome controls radiationinduced cell death and tissue injury. Science. 2016;354:765-8.

52. Reca R, Mastellos D, Majka M, Marquez L, Ratajczak J, Franchini $\mathrm{S}$, et al. Functional receptor for $\mathrm{C} 3 \mathrm{a}$ anaphylatoxin is expressed by normal hematopoietic stem/progenitor cells, and C3a enhances their homing-related responses to SDF-1. Blood. 2003;101:3784-93.

53. Wysoczynski M, Ratajczak J, Pedziwiatr D, Rokosh G, Bolli R, Ratajczak MZ. Identification of heme oxygenase 1 (HO-1) as a novel negative regulator of mobilization of hematopoietic stem/ progenitor cells. Stem Cell Rev Rep. 2015;11:110-8.

54. Corriden R, Chen Y, Inoue Y, Beldi G, Robson SC, Insel PA, et al. Ecto-nucleoside triphosphate diphosphohydrolase 1 (E-NTPDase1/CD39) regulates neutrophil chemotaxis by hydrolyzing released ATP to adenosine. J Biol Chem. 2008;283: 28480-6. 